\title{
Dual-targeted NIS polyplexes-a theranostic strategy toward tumors with heterogeneous receptor expression
}

\author{
Sarah Urnauer ${ }^{1} \cdot$ Kathrin A. Schmohl ${ }^{1}$ - Mariella Tutter ${ }^{1} \cdot$ Christina Schug $^{1} \cdot$ Nathalie Schwenk $^{1} \cdot$ Stephan Morys $^{2}$. \\ Sibylle Ziegler ${ }^{3} \cdot$ Peter Bartenstein $^{3} \cdot$ Dirk-André Clevert $^{4} \cdot$ Ernst Wagner $^{2} \cdot$ Christine Spitzweg $^{1}$
}

Received: 11 August 2018 / Revised: 20 December 2018 / Accepted: 26 December 2018 / Published online: 25 January 2019

(c) Springer Nature Limited 2019

\begin{abstract}
Tumor heterogeneity, within and between tumors, may have severe implications for tumor therapy, especially for targeted gene therapy, where single-targeted approaches often result in limited efficacy and therapy resistance. Polymer-formulated nonviral vectors provide a potent delivery platform for cancer therapy. To improve applicability for future clinical use in a broad range of patients and cancer types, a dual-targeting approach was performed. Synthetic LPEI-PEG $2 \mathrm{kDa}$-based polymer backbones were coupled to two tumor-specific peptide ligands GE11 (EGFR-targeting) and cMBP (cMET-targeting). The dual-targeting approach was used to deliver the theranostic sodium iodide symporter (NIS) gene to hepatocellular cancer. NIS as auspicious theranostic gene allows noninvasive imaging of functional NIS gene expression and effective anticancer radioiodide therapy. Enhanced tumor-specific transduction efficiency of dual-targeted polyplexes compared to singletargeted polyplexes was demonstrated in vitro using tumor cell lines with different EGFR and cMET expression and in vivo by ${ }^{124}$ I-PET-imaging. Therapeutic efficacy of the bispecific concept was mirrored by significantly reduced tumor growth and perfusion, which was associated with prolonged animal survival. In conclusion, the dual-targeting approach highlights the benefits of a bifunctional strategy for a future clinical translation of the bioimaging-based NIS-mediated radiotherapy allowing efficient targeting of heterogeneic tumors with variable receptor expression levels.
\end{abstract}

\section{Introduction}

Hepatocellular cancer (HCC), one of the most common cancers worldwide, is characterized by high mortality and resistance to conventional chemo- and radiotherapies [1].

The laboratory work was done at the Department of Internal Medicine IV and the Department of Pharmacy, Center of Drug Research, Pharmaceutical Biotechnology, LMU Munich, Munich, Germany.

Christine Spitzweg

christine.spitzweg@med.uni-muenchen.de

1 Department of Internal Medicine IV, University Hospital of Munich, LMU Munich, Germany

2 Department of Pharmacy, Center of Drug Research, Pharmaceutical Biotechnology, LMU Munich, Germany

3 Department of Nuclear Medicine, University Hospital of Munich, LMU Munich, Germany

4 Department of Clinical Radiology, University Hospital of Munich, LMU Munich, Germany
The limited success of available treatment options is attributed to the complex prooncogenic microenvironment of chronic liver diseases that often proceed the development of HCC, as well as the high level of tumor heterogeneity $[2,3]$. Tumor heterogeneity not only occurs between patients, but even between primary tumor and metastases and within the tumor itself and represents a major hurdle for the development of effective therapy strategies for HCC patients [2]. Against this background, even individualized and molecularly targeted therapy strategies as promising novel approaches for HCC treatment have to be designed in a way that takes heterogeneous tumor characteristics into account.

One promising strategy to minimize the effect of tumor heterogeneity and resistance to cancer therapies in the clinical setting is the combination of different therapeutics that either show different pharmacological modes of action or have different targets [4]. In the present study, a dualreceptor targeting strategy for a single nanotherapeutic using LPEI-PEG $\mathrm{kDDa}$-based nonviral vectors for delivery of the potent theranostic sodium iodide symporter (NIS) gene was developed. To reduce the impact of variable receptor 
expression levels due to inter- and intra-tumoral heterogeneity, GE11 and cMBP were chosen as ligands for EGFR- and cMET-targeting, respectively. Both ligands proved to be highly specific and effective in single-targeting experiments [5-10]. By simultaneously targeting both receptors, the postulated crosstalk between cMET/HGFR and EGFR [11] and enhanced particle uptake by receptor crosslinking that mimics biphasic uptake of viral vectors by binding to two different receptor types, can be exploited to increase efficacy [12-14].

Nonviral delivery vectors have been confirmed as potent agents for the delivery of genes specifically to tumor cells for cancer gene therapy. High precision synthesis allows the design of multifunctional systems for effective tumor cell targeting [15]. Functional groups for nucleic acid binding, as well as endosomal buffering can be complemented by a shielding domain that improves in vivo biocompatibility and lateral stabilization by crosslinking of polyplexes [16, 17]. Most importantly for specific tumor targeting, incorporation of active targeting ligands provides the mechanistic rationale to enhance tumor-specific binding, cellular uptake and transfection efficiency. Various ligands that bind receptors that are highly expressed in a wide range of tumors, including epidermal growth factor receptor (EGFR), cMET/hepatocyte growth factor receptor (HGFR), transferrin receptor, integrin receptors and folate receptor, have served as promising candidates for molecularly targeted cancer gene therapy [5, 7-10, 17-19]. Nevertheless, efficacy of nanoparticle-based carriers often varies after translation from in vitro conditions to in vivo models and between different tumor models [20], which is most likely attributable to tumor heterogeneity.

Since its cloning in 1996 [21], NIS has proven its function as potent theranostic gene and is already being investigated clinically in cancer patients [21-28]. The transduction efficiency in vitro and in vivo can be monitored by taking advantage of the reporter function of NIS that allows determination of radionuclide uptake in transfected cells and consequently gives the possibility of monitoring the gene delivery function. This further enables exact localization of tumorous tissue by noninvasive bioimaging as well as quantification of trapped radionuclides $\left({ }^{125} \mathrm{I},{ }^{123} \mathrm{I},{ }^{124} \mathrm{I},{ }^{18} \mathrm{~F}-\mathrm{TFB}\right)$. At the same time, NIS provides the basis for an effective treatment strategy by application of ${ }^{131} \mathrm{I},{ }^{188} \mathrm{Re}$, and ${ }^{211}$ At $[29,30]$.

In the current study, nonviral NIS gene transfer was investigated in vitro in different tumor cell lines by comparison of the dual-targeting strategy to single-targeting of EGFR or cMET. Based on these results, the efficacy of polyplexes for dual-targeting and single-targeting was further examined in an orthotopic in vivo model of $\mathrm{HCC}$ using the reporter function of NIS for noninvasive positron emission tomography (PET) imaging followed by evaluation of the therapeutic efficacy of the dual-targeting approach.
This novel approach utilizes two bifunctional strategies: (1) simultaneous targeting of two receptors to improve efficacy and reduce effects of variable receptor expression levels in heterogeneic tumors and (2) using the dual function of NIS for monitoring of the efficiency of gene delivery by noninvasive imaging of tumoral NIS expression as well as effectiveness of therapeutic intervention after application of ${ }^{131} \mathrm{I}$ for cancer treatment.

\section{Materials and methods}

\section{Plasmid and polymer synthesis and polyplex formation}

Polymers with LPEI-PEG ${ }_{2 \mathrm{kDa}}$-backbone were synthesized by coupling heterobifunctional (poly)ethylene glycol (NHSPEG-OPSS, $2 \mathrm{kDa}$, Rapp Polymere GmbH, Tübingen, Germany) to amine groups of linear polyethylene imine (LPEI) via N-hydroxy succiniminyl ester followed by a cation exchange chromatography purification step as described previously $[7,18]$. Specific targeting was achieved by coupling peptide ligands to the polymer backbone. GE11 was used for EGFR-targeting (LPEI-PEG-GE11; peptide sequence: YHWYGYTPQNVI) and cMBP was applied for cMETtargeting (LPEI-PEG-cMBP; peptide sequence: KSLSRHDHIHHH). The conjugates were stored at $-80^{\circ} \mathrm{C}$ as $1-5 \mathrm{mg} / \mathrm{ml}$ stock solutions until further use. Polyplexes were formed by complexing polymer with codon-optimized human NIS plasmid DNA [6, 18]. Polymers and cDNA, diluted in the same volumes of HEPES (2-[4-(2-hydroxyethyl)piperazin-1-yl]ethanesulfonic acid)-buffered glucose (HBG: $20 \mathrm{mmol} / \mathrm{l} \mathrm{HEPES,} \mathrm{5 \%} \mathrm{(w/v)} \mathrm{glucose} \mathrm{at} \mathrm{pH}$ 7.4) at a nitrogen/phosphate $(\mathrm{N} / \mathrm{P})$ ratio of $6(\mathrm{w} / \mathrm{w})$, were mixed and incubated at room temperature for $20 \mathrm{~min}$ prior to use [31].

For single-targeted polyplex solutions, $100 \%$ of polymer was added, for dual-targeted polyplexes a mixture of 50\% cMET-targeted and 50\% EGFR-targeted polymers was prepared (total $\mathrm{N} / \mathrm{P}=6$ ) before complexing with pDNA. For in vitro studies the DNA concentration for polyplex formation was $2 \mu \mathrm{g} / \mathrm{ml}$, for in vivo studies $200 \mu \mathrm{g} / \mathrm{ml}$.

\section{Particle size measurements}

Particle sizes of single-targeted and dual-targeted polyplexes were determined by transmission emission microscopy (TEM; JEM 1011, Jeol, Freising, Germany). Samples were prepared with $1 \mu \mathrm{g}$ DNA in a total volume of $100 \mu$ l. The formvar/carbon coated 300 mesh copper grids (Ted Pella Inc., Redding, USA) were activated by mild plasma cleaning. Subsequently, the grids were incubated for $1 \mathrm{~min}$ with $20 \mu \mathrm{l}$ of the polyplex solution. Excess liquid was blotted off using filter paper until the grid was almost dry. 
Then, the grids were washed with $5 \mu \mathrm{l}$ of staining solution for $5 \mathrm{~s}$ and incubated for $20 \mathrm{~s}$ with $5 \mu \mathrm{l}$ of a $2 \%$ aqueous uranyl formate solution. Excess liquid was blotted off using filter paper, followed by air-drying for $30 \mathrm{~min}$. TEM was performed at $80 \mathrm{kV}$.

\section{Cell culture}

The HCC cell line HuH7 (JCRB0403; Japanese Collection of Research Bioresources Cell Bank, Osaka, Japan) was cultured in Dulbecco's modified eagle medium (DMEM; $1 \mathrm{~g} / 1$ glucose; Sigma-Aldrich, St. Louis, Missouri, USA). The breast cancer cell line MCF-7 (American Type Culture Collection, Manassas, Virginia, USA) was cultured in DMEM (4 g/l glucose; Sigma-Aldrich). The human follicular thyroid carcinoma cell line FTC-133 (Sigma-Aldrich) was cultured in DMEM/F12 (Sigma-Aldrich). All media were supplemented with $10 \%(\mathrm{v} / \mathrm{v})$ fetal bovine serum (FBS Superior, Biochrom/Merck Millipore, Berlin, Germany) and $1 \%(\mathrm{v} / \mathrm{v})$ penicillin/streptomycin (Sigma-Aldrich).

Cells were maintained at $37^{\circ} \mathrm{C}$ and $5 \% \mathrm{CO}_{2}$ in an incubator with a relative humidity of $95 \%$. Cell culture medium was replaced every second day and cells were passaged at $80 \%$ confluency.

\section{EGFR and CMET receptor expression levels in vitro}

In total, $0.8-1 \times 10^{6}$ cells were detached with trypsin/EDTA (Sigma-Aldrich), washed with phosphate buffered saline (PBS; Sigma-Aldrich), supplemented with 10\% FBS (Sigma-Aldrich) and incubated with an EGFR-specific antibody (1:200; monoclonal mouse IgG1, Dako, Glostrup, Denmark) or with an antibody that detects human cMET/HGFR (1:200; monoclonal mouse IgG1, R\&D Systems, Minneapolis, Minnesota, USA) or with an IgG-antimouse antibody (1:200; BD Biosciences, Franklin Lakes, New Jersey, USA) as negative control for $1 \mathrm{~h}$ on ice. Then, cells were washed with PBS with 10\% FBS and incubated with an AlexaFluor 488 labeled goat anti-mouse secondary antibody (1:400; Invitrogen, Langenselbold, Germany) for $1 \mathrm{~h}$ on ice. Cells were washed and resuspended in PBS with $10 \%$ FBS for analysis, which was performed on a BD Accuri C6 flow cytometer (BD Biosciences). Cells were gated by forward/sideward scatter and pulse width for exclusion of doublets. PI (propidium iodide; SigmaAldrich) was used for discrimination between viable and dead cells.

\section{Cellular binding and internalization}

Cells were seeded in 24-well plates at a density of 50,000 cells per well. After $24 \mathrm{~h}$, cell culture medium was replaced with $400 \mu \mathrm{l}$ fresh growth medium. Cells were transfected with polyplexes for single-targeting, i.e., LPEI-PEG-GE11/ NIS or LPEI-PEG-cMBP/NIS (subsequently specified as EGFR-targeting or cMET-targeting respectively) or polyplexes formed with a 1:1 mixture of polymers for simultaneous cMET- and EGFR-targeting (subsequently labeled as dual-targeting). HBG served as control. For pDNA polyplexes $(\mathrm{N} / \mathrm{P}=6)$ in $100 \mu \mathrm{l}$ HBG $1 \mu \mathrm{g}$ pDNA was used, where $20 \%$ of the nucleic acid was Cy5-labeled. To determine cellular association, polyplexes were added to cells and incubated for $30 \mathrm{~min}$ on ice. Afterwards, cells were washed twice with $500 \mu \mathrm{l}$ PBS, detached with trypsin/EDTA and resuspended in PBS with 10\% FBS.

For cell uptake experiments, cells were incubated for 30 min with polyplexes. Cells were then washed with $500 \mu \mathrm{l}$ PBS/1000 I.U. heparin for $15 \mathrm{~min}$ on ice to remove polyplexes on the cell surface. Cells were then detached with trypsin/EDTA and taken up in PBS with $10 \%$ FBS.

Samples were examined on a BD Accuri C6 flow cytometer by determination of the excitation of Cy5 at $635 \mathrm{~nm}$ and detection of emission at $665 \mathrm{~nm}$. Cells were gated by forward/sideward scatter and pulse width for exclusion of doublets. PI was used to discriminate between viable and dead cells.

\section{Transfection studies}

Cells were plated at a density of $2 \times 10^{5}$ cells per well in 6well plates and incubated for $45 \mathrm{~min}$ with polyplexes for dual-targeting or single EGFR- or cMET-targeting. Transfection efficiency was determined by measurement of iodide uptake activity at steady-state conditions $24 \mathrm{~h}$ after transfection as described previously [22]. Pretreatment of cells with the NIS-specific inhibitor perchlorate $\left(\mathrm{NaClO}_{4}\right)$ was performed to verify NIS-mediated iodide uptake.

\section{Cell viability assay}

Cell viability $24 \mathrm{~h}$ after transfection was analyzed after incubation of cells with a commercially available MTT reagent (Sigma-Aldrich) for $2 \mathrm{~h}$ at $37^{\circ} \mathrm{C}$ followed by a washing step with PBS. The formazan product was measured after incubation with $10 \%$ DMSO (v/v) (dimethyl sulfoxide; Sigma) in isopropanol at $620 \mathrm{~nm}$ in a Sunrise microplate absorbance reader (Tecan, Männedorf, Switzerland).

\section{Establishment of orthotopic HuH7 xenografts}

For orthotopic HCC xenografts in female CD-1 nu/nu mice (Charles River, Sulzfeld, Germany), $1 \times 10^{6} \mathrm{HuH7}$ cells resuspended in $50 \mu \mathrm{l}$ were injected into the liver after laparotomy of 7-week-old mice under full anesthesia. Animals were pre- and post-treated with Metacam $(0.5 \mathrm{mg} / \mathrm{kg})$. Mice were sacrificed when healthy liver tissue dropped 
below $30 \%$ as determined by sonography or animals showed any other symptoms of illness. Animals were maintained under specific pathogen-free conditions with access to mouse chow and water ad libitum. The experimental protocol was approved by the regional governmental commission for animals (Regierung von Oberbayern) and all animal experiments were carried out according to the guidelines of the German law of protection of animal life.

\section{EGFR and CMET receptor expression levels in vivo}

Receptor immunofluorescence staining was performed on dissected frozen tumor tissues. Tissues were fixed in $80 \%$ methanol for $5 \mathrm{~min}$ at $4{ }^{\circ} \mathrm{C}$ and acetone for $2 \mathrm{~min}$ at $-20^{\circ} \mathrm{C}$. PBS was used for rehydration and sections were blocked with $12 \%$ bovine serum albumin/PBS for $30 \mathrm{~min}$ at room temperature. An EGFR-specific antibody (1:100; monoclonal mouse IgG, Dako) or a cMET-specific antibody (1:100; monoclonal mouse IgG1, R\&D Systems) were used and sections were incubated for $1 \mathrm{~h}$. Afterwards, sections were incubated with an anti-mouse Alexa488-conjugated secondary antibody (1:200; BD Pharmingen, Heidelberg, Germany). For nuclei counterstaining Hoechst bisbenzimide (1:1000; $5 \mathrm{mg} / \mathrm{ml}$, Sigma-Aldrich) was applied and sections were embedded in Fluorescent Mounting Medium (Dako). Stained sections were examined using an Axiovert $135 \mathrm{TV}$ fluorescence microscope equipped with an AxioCam MRm CCD camera and AxioVision Rel. 4.8 software (Carl Zeiss, Munich, Germany).

\section{PET imaging studies after systemic NIS gene transfer in vivo}

Experiments started 5-6 weeks after intrahepatic injection of tumor cells. For determination of tumor specific NIS expression and subsequent NIS-mediated iodide uptake, animals received LPEI-PEG-GE11/NIS polyplexes for EGFR-targeting $(n=6)$, LPEI-PEG-cMBP/NIS for cMETtargeting $(n=4)$ or both for dual-targeting $(n=7)$. Polyplexes were administered systemically via the tail vein (intravenously, i.v.) at a DNA dose of $2.5 \mathrm{mg} / \mathrm{kg}(50 \mu \mathrm{g}$ DNA in $250 \mu \mathrm{L} \mathrm{HBG}$ ). At $48 \mathrm{~h}$ after polyplex injection mice received the NIS-specific PET tracer ${ }^{124}$ I and accumulation in tumor tissue was determined by small-animal PET (Inveon, SIEMENS Preclinical Solutions, Erlangen, Germany). Serial scanning was performed after 1,3 , and $5 \mathrm{~h}$. Regions of interest were analyzed with the software Inveon Acquisition Workplace (Siemens), quantified using Inveon Research Workplace (Siemens) and expressed as a fraction of the total amount of initial dose (\% of ID). To suppress thyroidal iodide uptake, a 10-day pretreatment with L-thyroxine (L-T4; $5 \mathrm{mg} / \mathrm{ml}$; Sigma-Aldrich) in drinking water was conducted before PET-imaging. To verify NIS-specific uptake, pretreatment with an intraperitoneal (i.p.) injection of $2 \mathrm{mg}$ of the competitive NIS inhibitor sodium perchlorate $\left(\mathrm{NaClO}_{4}\right) 30$ min before PET tracer administration $(n=2)$ was performed.

\section{Immunohistochemical analysis of NIS protein expression}

Immunohistochemical NIS staining of paraffin embedded tumor tissue derived from hepatic tumor sections after NIS gene delivery was performed using a mouse monoclonal antibody directed against human NIS (1:1000; Merck Millipore) as described previously [32, 33]. Immunohistochemically stained sections were imaged on an Olympus BX41 microscope equipped with an Olympus XC30 CCD camera (Olympus, Shimjukum Tokio, Japan).

\section{Radioiodide therapy studies}

Three weeks after intrahepatic tumor cell injection, when mice had received a 10-day pretreatment with L-T4 in drinking water, therapy trials were started. Animals were randomly distributed to two groups. Animals received an i.v. injection of a solution of polplexes for dual-targeting followed by an i.p. application of $55.5 \mathrm{MBq}{ }^{131} \mathrm{I}(n=8)$ or saline $(n=8) 48 \mathrm{~h}$ later. The cycle consisting of systemic NIS gene transfer followed by radioiodide was repeated for a total of three times on days $0 / 2,3 / 5$, and $7 / 9$.

Tumor growth was monitored by conventional sonography and tumor perfusion was determined by contrastenhanced ultrasound (CEUS) after application of $100 \mu \mathrm{l}$ of the contrast agent SonoVue ${ }^{\circledR}$ (Bracco, Cadempino, Switzerland) on an Acuson Sequoia 512 (Siemens) combined with a $15 \mathrm{~L} 8 \mathrm{~W}$ ultrasound probe using the Cadence contrast pulse sequencing technology.

The experiment was performed in a blinded experimental setup and evaluated by an experienced radiologist. CEUS was performed as described previously [34] and the contrast agent concentration was estimated using pre-defined calibration curves [35]. Mice were sacrificed when healthy liver tissue was reduced to $<30 \%$ or when mice showed other signs of illness.

\section{Indirect immunofluorescence assay}

Immunofluorescence staining of Ki67 and CD31 was performed on dissected frozen tumor tissues as described previously [6]. For Ki67, a rabbit polyclonal antibody against human Ki67 (1:200; Abcam, Cambridge, UK) and an antirabbit Alexa488-conjugated secondary antibody (1:400; Jackson ImmunoResearch, West Grove, Pennsylvania, USA) were used. For CD31, a rat monoclonal antibody against mouse CD31 (1:200; BD Pharmingen) was used. For 

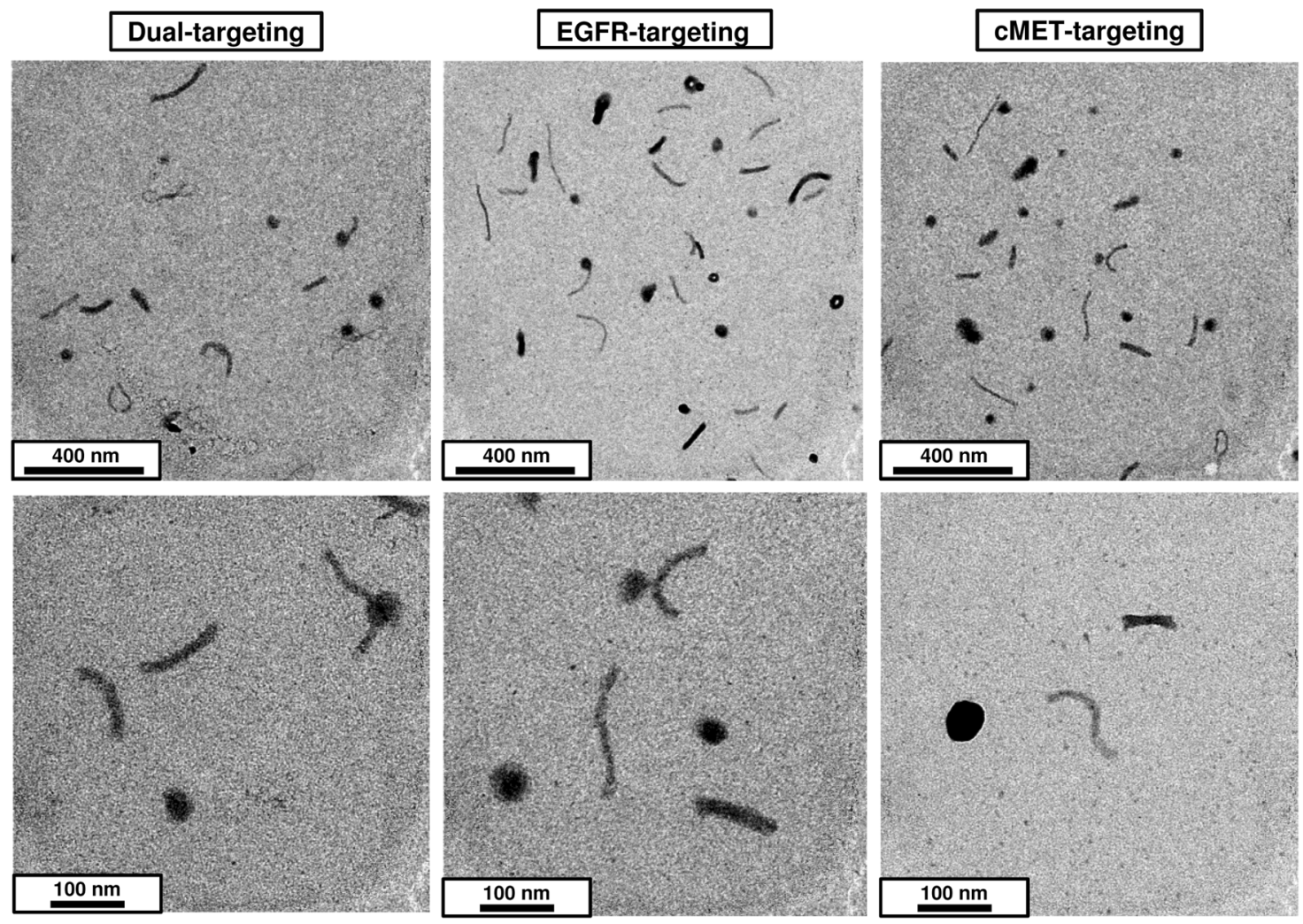

Fig. 1 Particle size measurements. TEM size measurements of formed polyplexes revealed two different particle subtypes with no significant differences between the polyplex solutions for dual- or single-

targeting. Globular particles were $\sim 50 \mathrm{~nm}$ in size and linear particles were up to $200 \mathrm{~nm}$ in size

detection, an anti-rat Cy3-conjugated secondary antibody (1:400; Jackson ImmunoResearch) was applied. Hoechst bisbenzimide $(1: 1000 ; 5 \mathrm{mg} / \mathrm{ml})$ was used for nuclei counterstaining and sections were embedded in Fluorescent Mounting Medium (Dako). ImageJ software (NIH, Bethesda, MD, USA) was used for quantification of proliferation (Ki67-staining) and blood vessel density (CD31-staining) by analyzing six visual fields per tumor section of every mouse.

\section{Statistics}

All in vitro experiments were carried out at least in triplicates. Results are expressed as mean $\pm \mathrm{SEM}$, mean fold change \pm SEM and, for survival plots, in percent. Statistical significance was calculated by two-tailed Student's $t$-test. $p$-values $\leq 0.05$ were considered significant $\left({ }^{*} p \leq 0.05\right.$; $* * p \leq 0.01 ; * * * p \leq 0.001)$.

\section{Results}

\section{Particle sizes}

To investigate whether different solutions of polyplexes result in unequal particle sizes, TEM measurements were

performed. All three polyplex solutions for EGFR-targeting, cMET-targeting and dual-targeting were analyzed. No significant differences between the three solutions were observed and TEM measurements revealed two different particle subtypes: linear and round particles. Sizes of globular particles were determined to be $\sim 50 \mathrm{~nm}$ and sizes of linear particles were analyzed to be $15-20 \mathrm{~nm}$ thin and up to $200 \mathrm{~nm}$ long (Fig. 1).

\section{EGFR and CMET expression levels}

Three different cell lines were used for subsequent in vitro studies and were investigated for EGFR and cMET expression levels. The human HCC cell line $\mathrm{HuH7}$ and the human breast cancer cell line MCF-7 were identified to have both obvious EGFR and cMET cell surface expression. In contrast, the human follicular thyroid carcinoma cell line FTC-133 showed low expression levels for both receptors (Fig. 2).

\section{Comparison of dual-targeting and single-targeting for NIS gene transfer in vitro}

The three different human tumor cell lines were transfected with polyplex solutions to investigate single-targeting vs. 

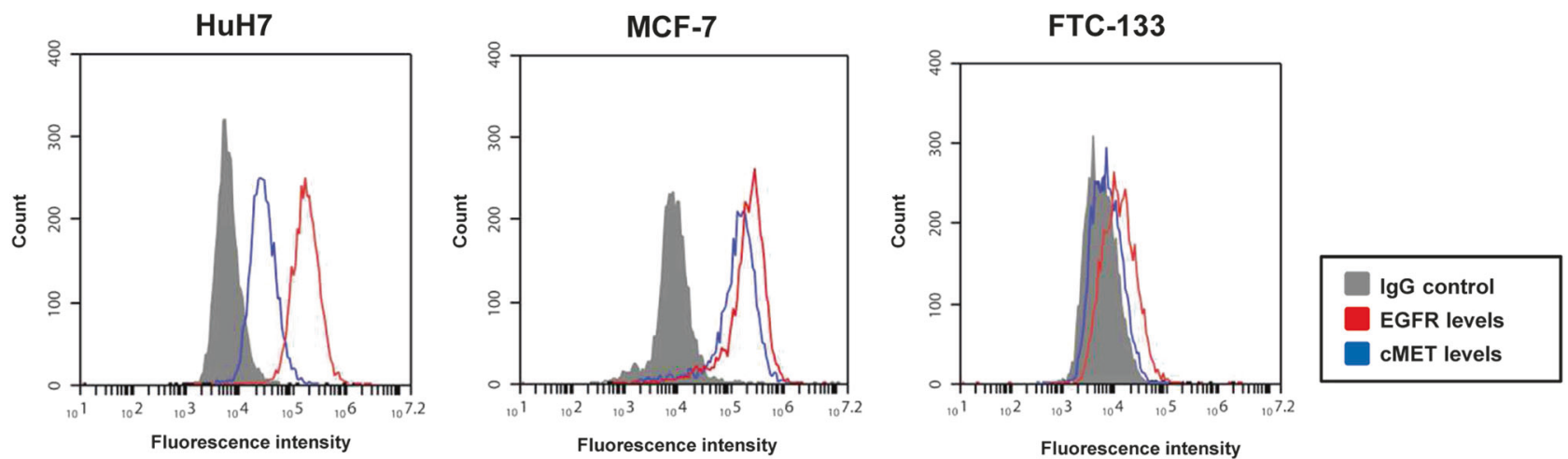

Fig. 2 EGFR and cMET expression levels. The human HCC cell line $\mathrm{HuH7}$, the human breast cancer cell line MCF-7 and the human follicular thyroid carcinoma cell line FTC-133 were investigated for EGFR and cMET expression levels by flow cytometry. HuH7 and

dual-targeting in relation to cell surface receptor expression. Transfection conditions using single- and dual-targeted polyplexes were optimized in $\mathrm{HuH7}$ cells by measurement of perchlorate-sensitive iodide uptake activity $24 \mathrm{~h}$ after application of polyplexes. An N/P ratio of $6(\mathrm{w} / \mathrm{w})$ was found to result in highest transfection efficiency at lowest cell cytotoxicity (data not shown).

Cellular binding and cellular uptake were measured by detection of fluorescence intensity of polyplexes containing Cy5-labeled NIS DNA (Fig. 3a-c). Binding was measured after a short incubation time of $30 \mathrm{~min}$ and revealed higher mean fluorescence intensity (MFI) values for dual-targeting (black bars), whereas MFI values for the single-targeted polyplexes, especially EGFR, were lower (Fig. 3d; red bars for EGFR-targeting, blue bars for cMET-targeting). In the low EGFR and cMET-expressing cell line FTC-133, the dual-targeting strategy resulted in lower MFI values than obtained after single cMET-targeting transfection (Fig. 3d).

Uptake levels confirmed the trend seen in the binding studies, as a significantly higher MFI was detected for $\mathrm{HuH} 7$ and MCF-7 cells (Fig. 3e-g). In FTC-133, dual-targeting led to similar (compared to EGFR-targeting) or decreased (compared to cMET-targeting) MFI levels (Fig. 3h).

Iodide uptake verified the results from the flow cytometry experiments in the three cell lines, with more pronounced uptake in $\mathrm{HuH7}$ (Fig. 3i) and significantly increased uptake in MCF-7 (Fig. 3j) after simultaneously targeting EGFR and cMET. In the low EGFR and cMET-expressing FTC-133 cell line, no advantage of dual- over single-targeting was observed (Fig. 3k). Cell viability was not affected by $45 \mathrm{~min}$ incubation with the different polyplexes (Fig. 31-n).

\section{Induction of iodide accumulation after systemic tumor-targeted NIS gene transfer in vivo}

Based on the promising in vitro results, the dual-targeting strategy was further evaluated in vivo. An orthotopic $\mathrm{HuH} 7$
MCF-7 cells were found to have both high EGFR and cMET cell surface expression. FTC-133 cells showed low receptor expression levels for cMET and EGFR. An IgG-anti-mouse antibody served as control

liver tumor model was established that showed obvious EGFR (Fig. 4a) and cMET (Fig. 4b) expression. Tumorbearing mice were systemically injected with either polyplexes for single-receptor targeting or dual-targeting. Fortyeight hours after NIS gene transfer, mice were injected i.p. with ${ }^{124} \mathrm{I}$ and radioiodide biodistribution was assessed by small-animal PET-imaging. Images $1 \mathrm{~h}$ after iodide application showed improved distribution and uptake of iodide in tumors of mice that received polyplexes for dual-targeting (Fig. 4c), in comparison to tumors of mice treated with single-targeted polyplexes (Fig. 4d, e). Physiological expression of NIS in thyroid and stomach leads to iodide accumulation in these tissues and renal elimination of radioiodide causes a signal in the bladder. NIS-specificity was verified by i.p. application of the NIS-specific inhibitor sodium perchlorate $30 \mathrm{~min}$ prior to radionuclide application in mice treated with dual-targeted polyplexes, which resulted in an almost complete inhibition of iodide uptake in the tumor and organs that physiologically express NIS (Fig. 4f). No additional iodide uptake was recorded in nontarget organs such as lung, liver, kidney, and spleen

Regions of interest (ROI) were quantified and as soon as 1 $\mathrm{h}$ after iodide application, a considerably more pronounced tumoral iodide uptake was observed in tumors of mice that received polyplexes for dual-targeting $(4.9 \pm 0.6 \%$ of ID). Lower levels were obtained in tumors of mice treated with polyplexes for single EGFR-targeting $(4.7 \pm 0.7 \%$ of ID) and cMET-targeting ( $3.2 \pm 0.3 \%$ of ID). After $3 \mathrm{~h}$, tumors of mice treated with polyplexes for dual-targeting $(3.0 \pm 0.4 \%$ of ID) showed a more robust mean iodide uptake compared to animals after single-targeting (EGFR-targeting: $2.4 \pm 0.5 \%$ of ID; cMET-targeting: $2.3 \pm 0.3 \%$ of ID). ${ }^{124}$ I scans $5 \mathrm{~h}$ after tracer application still showed significantly higher iodide uptake levels demonstrating prolonged tumoral iodide uptake after dual-targeting ( $2.0 \pm 0.4 \%$ of ID) compared to EGFR- (1.0 \pm $0.1 \%$ of ID) and cMET-targeting (1.5 $\pm 0.3 \%$ of ID) (Fig. $4 \mathrm{~g}$ ). (Fig. 4c-f). 


\begin{tabular}{llll} 
Cellular binding & Cellular uptake & lodide uptake activity & Cell viability \\
\hline
\end{tabular}

\section{HuH7}

A

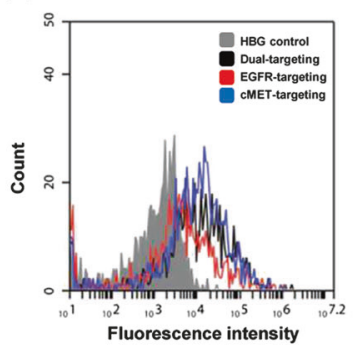

MCF-7

B

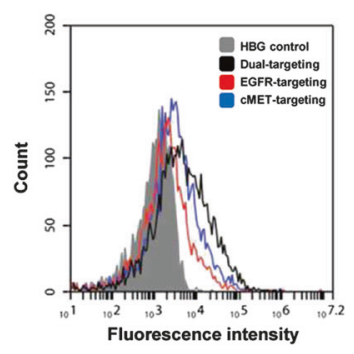

FTC-133

C
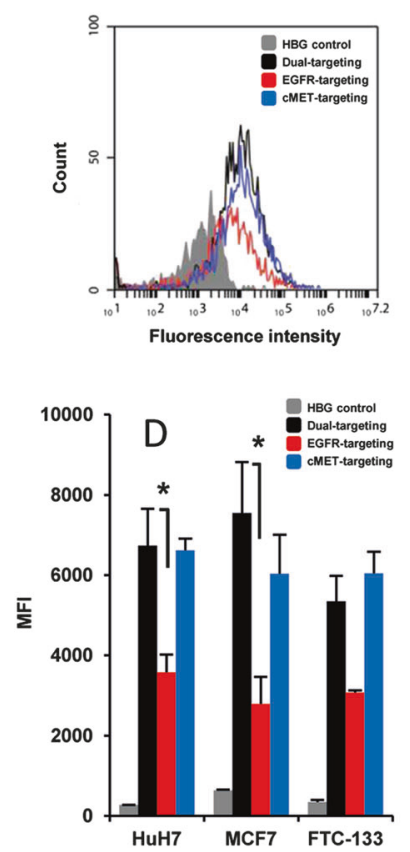

$E$

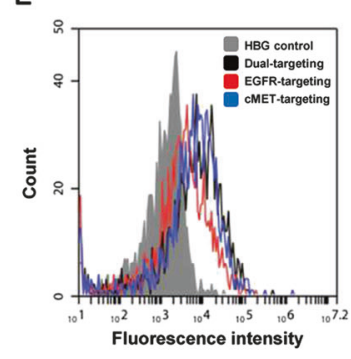

F

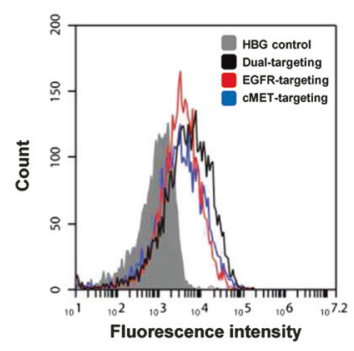

G
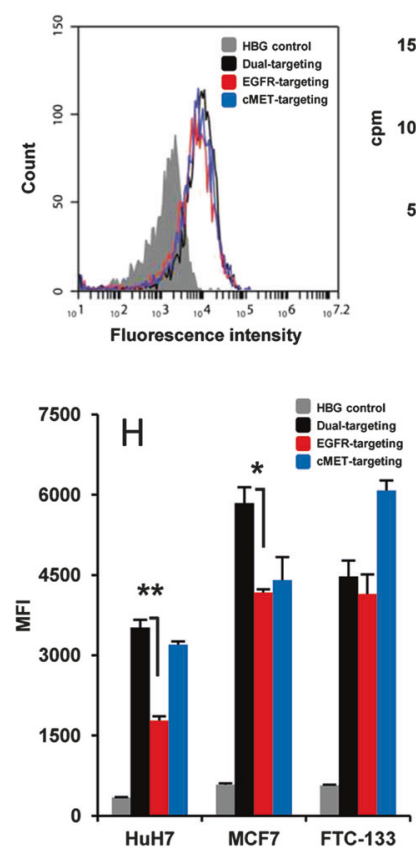
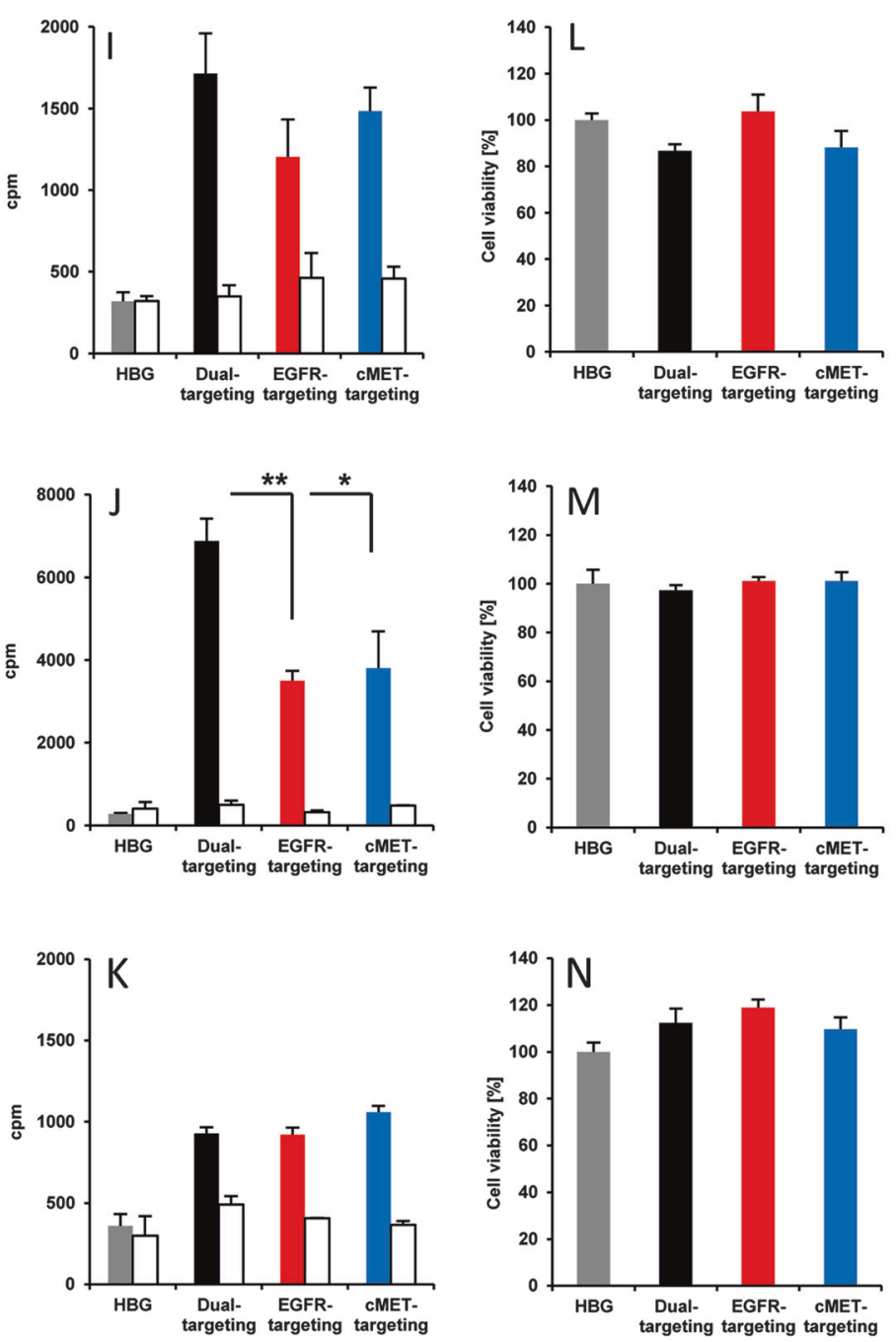

\section{Tumor-specific NIS protein expression}

After the imaging studies, mice from the three different treatment groups were sacrificed and tumors dissected. Immunohistochemical staining of intrahepatic tumor

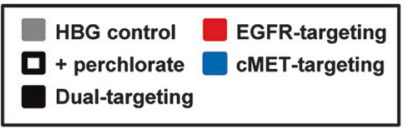

sections revealed NIS-specific staining in all three treatment groups (Fig. 5).

In tumors from mice treated with polyplexes for dualtargeting, NIS-specific immunostaining was observed as clusters of membrane-associated as well as cytoplasmic NIS 
Fig. 3 Cellular binding, uptake and transfection efficacy of polyplexes for dual-targeting vs. single-targeting. Transfection efficiency of polyplexes for single- and dual-targeting was investigated. Cellular binding and cellular uptake were measured by detection of fluorescence intensity of polyplexes containing Cy5-labeled NIS DNA. In high receptor expressing cell lines, binding studies revealed higher mean fluorescence intensity (MFI) values for dualtargeted polyplexes (black bars), whereas MFI values for singletargeted polyplexes were lower (red bars for EGFR-targeting, blue bars for cMET-targeting) $(\mathbf{a}, \mathbf{b}, \mathbf{d})$. This effect was not obtained with the low EGFR- and cMET-expressing cell line FTC-133 (c, d) $(n=3)$. Uptake levels confirmed binding studies, where a significantly higher MFI after transfection for dual-targeting was detected in $\mathrm{HuH7}$ and MCF-7 cells compared to FTC-133 (e-h) $(n=3)$. NIS-mediated ${ }^{125} \mathrm{I}$ uptake verified enhanced NIS expression after simultaneous targeting of EGFR and cMET in HuH7 and MCF-7 cells, while low iodide uptake activity was measured in FTC-133 cells $(\mathbf{i}-\mathbf{k})(n=4)$. No toxic effects were measured after incubation with the different polyplex mixtures for $45 \min (\mathbf{l}-\mathbf{n})(n=3)\left({ }^{*} p \leq 0.05 ; * * p \leq 0.01\right)$. Results are reported as mean \pm SEM

gene expression in the vicinity of blood vessels (Fig. 5, left panel). Also tumors from animals that were injected with single EGFR- (Fig. 5, middle panel) and cMET-targeting polyplexes (Fig. 5, right panel) showed NIS-specific immunoreactivity.

\section{Radioiodine therapy studies after in vivo NIS gene transfer}

After the proof of concept of effective tumoral NIS transduction using polyplexes for dual-targeting, the therapeutic effect of the dual-targeting NIS gene therapy concept after application of ${ }^{131} \mathrm{I}$ was assessed. Mice developing orthotopic liver carcinomas were treated according to an established treatment protocol [6]. Three weeks after tumor cell inoculation, mice in the therapy group received three cycles of dual-targeted polyplexes i.v. on days 0,3 , and 7, followed by i.p. injections of 55.5 $\mathrm{MBq}{ }^{131} \mathrm{I}$ on days 2,5 , and $9(n=8)$. Control mice received saline instead of iodide $(n=8)$. Four sonographic measurements were performed on days 2, 9, 15, and 23 after therapy start. Mice in the therapy group exhibited significantly reduced tumor growth (Fig. 6a, b) compared to the control group (Fig. 6a, c), which was associated with significantly prolonged survival up to 45 days after therapy start in comparison to 29 days in the control group (Fig. 6d).

When mice had to be sacrificed due to tumor growth, intrahepatic HCCs were dissected and further processed for immunofluorescence analysis. A Ki67-specific antibody (green) was used to identify tumor cell proliferation and an antibody against CD31 (red) served for blood vessel labeling (Fig. 6e). The application of dually targeted polyplexes followed by ${ }^{131} \mathrm{I}$ resulted in reduced proliferation and blood vessel density compared to tumors of mice treated with saline instead of iodide (Fig. 6e).

\section{Perfusion of intrahepatic tumors determined by CEUS}

Two weeks after the last treatment cycle, tumor perfusion was assessed to compare tumors from mice treated with polyplexes for dual-targeting that received ${ }^{131} \mathrm{I}$ with animals that received saline instead. Mice in the therapy group demonstrated an overall reduced contrast agent uptake and a lower maximum signal compared to mice that received saline (Fig. 7a). This was further associated with reduced peak enhancement (PE; 1432.7 \pm 534.6 ) (Fig. 7b), wash-in area under the curve (WiAUC; 7184.2 \pm 2197.6 ) (Fig. 7c) and retention time (RT; $7.98 \pm 0.97$ ) (Fig. 7d) of therapy animals in comparison to control animals (PE: 2425.9 \pm 260.5; WiAUC: $19633.4 \pm 1451.8 ; \quad$ RT: $11.39 \pm 0.71)$ (Fig. 7b-d).

\section{Discussion}

In the last decade, intensive research in the field of cancer gene therapy has made big strides toward novel therapeutic options. For clinical application of cancer gene therapy as novel therapeutic alternative, NIS has emerged as an ideal target gene, as it combines the features of a reporter and therapy gene. Due to its endogenous thyroidal expression, NIS has successfully been used over decades for the treatment of thyroid cancer [36]. The high amount of experience gained over the years allows a safe application in humans with a well-known therapeutic window and minimal side effects. Introducing NIS to non-thyroidal tumor cells offers the possibility to monitor tumor-specific NIS gene expression in a quantitative manner as well as exact localization of tumorous tissue by multimodal imaging techniques with various NIS-specific tracers [23, 25, 37]. At the same time, NIS expression enables application of therapeutic radionuclides $\left({ }^{131} \mathrm{I},{ }^{188} \mathrm{Re}\right)$ for the destruction of cancer cells. The high efficacy of the theranostic function of NIS after gene transfer to non-thyroidal tumors has been demonstrated in several preclinical studies [6-8, 18, 22, 29, 33, 34, 38-44] and showed first promising results in clinical trials after local administration of viral NIS gene delivery vectors [26].

However, in the growing sector of cancer gene therapy, tumor heterogeneity has turned out to be a major bottleneck, resulting in limited and diverging efficacy of therapies. Differences in morphological and phenotypic characteristics that define the behavior of the tumor lesion exist both between different tumors (inter-tumoral heterogeneity) and within tumors (intra-tumoral heterogeneity) [45]. On the molecular level, intra-tumoral heterogeneity is mirrored by diverging cell populations evolved from different subclones [46]. This often leads to great differences in surface receptor expression, release of growth factors and cytokines, cellular 

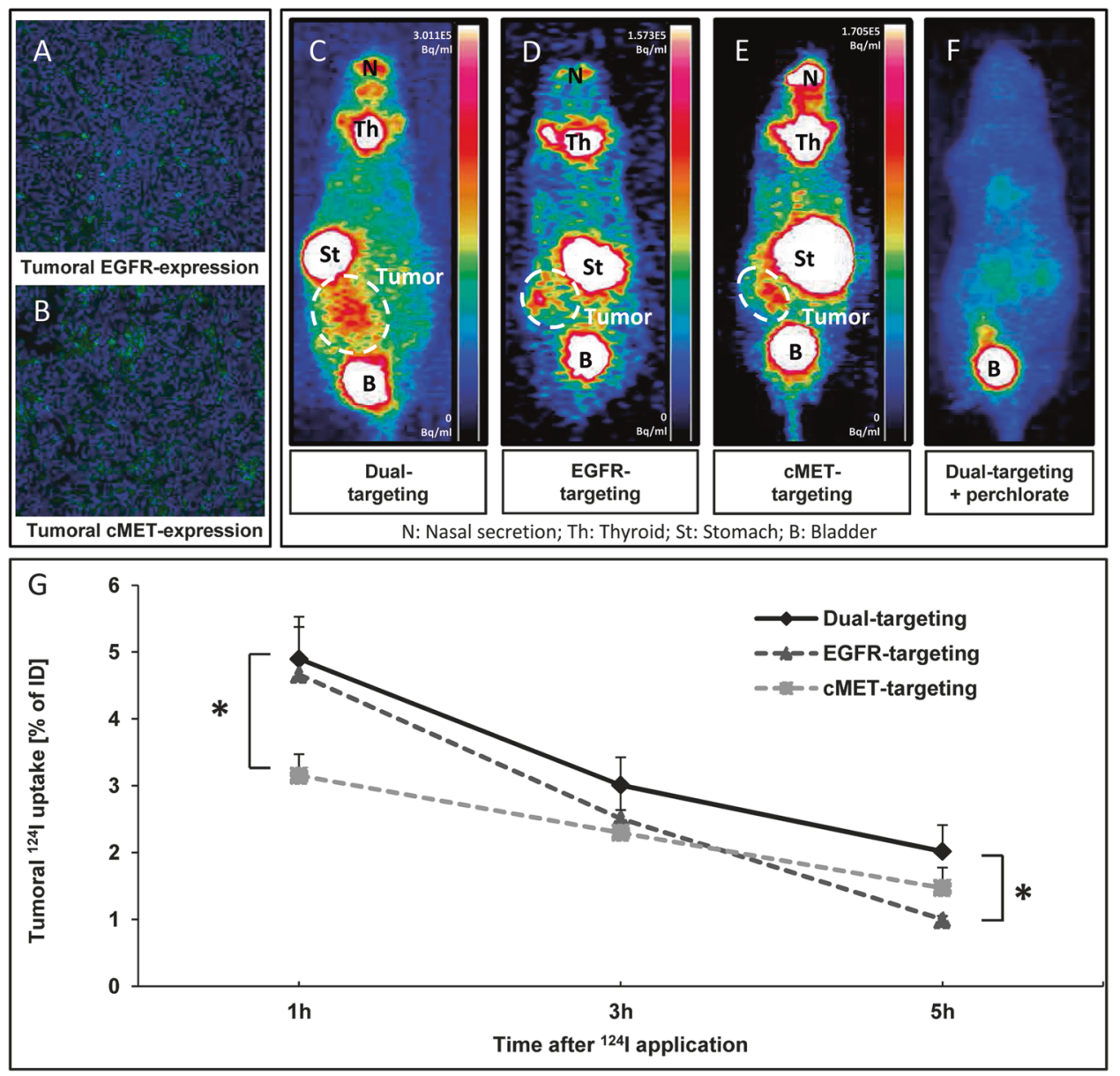

Fig. 4 Comparison of dual-targeting vs. single-targeting by smallanimal PET imaging after systemic NIS gene transfer in vivo. Mice bearing orthotopic $\mathrm{HuH} 7$ liver tumors that demonstrated obvious EGFR and cMET expression $(\mathbf{a}, \mathbf{b})$ received i.v. polyplexes for single EGFR-targeting $(n=6)$, single cMET-targeting $(n=4)$ or dualtargeting $(n=7)$. At $48 \mathrm{~h}$ after NIS gene transfer, mice were injected i.p. with $10 \mathrm{MBq}{ }^{124} \mathrm{I}$ and radioiodide biodistribution was assessed by small-animal PET imaging. PET images $1 \mathrm{~h}$ after iodide application showed improved distribution and uptake of iodide in tumors of mice that received polyplexes for dual-targeting in comparison to animals injected with single-targeted polyplexes (c-e). NIS-specificity was verified by pretreatment of mice that received polyplexes for dualtargeting with the NIS-specific inhibitor sodium perchlorate 30 min prior to radionuclide application $(n=2)$. This resulted in an almost complete inhibition of iodide uptake in the tumor and organs that physiologically express NIS (f). ROIs were quantified and higher tumoral iodide uptake over $5 \mathrm{~h}$ was observed in tumors of mice that received polyplexes for dual-targeting $\left({ }^{*} p \leq 0.05\right)$. Results are reported as mean $\%$ of $\mathrm{ID} \pm \mathrm{SEM}$

expression levels, nonviral vectors as potent novel gene delivery vehicles have to be designed and applied in a specialized manner for a future clinical translation. Formulation improvement includes the synthesis of a cationic carrier backbone for DNA binding, incorporation of hydrophilic domains for polyplex shielding and endosomal buffering and integration of targeting ligands that are indispensable for tumor-specific gene delivery. Variable expression patterns of ligand binding surface receptors are often responsible for heterogeneous response rates and expression levels of genetic information after targeted gene transfer. Bispecific targeting as well as combination of different therapy approaches are already well-established strategies in the clinical setting in the form of combination 


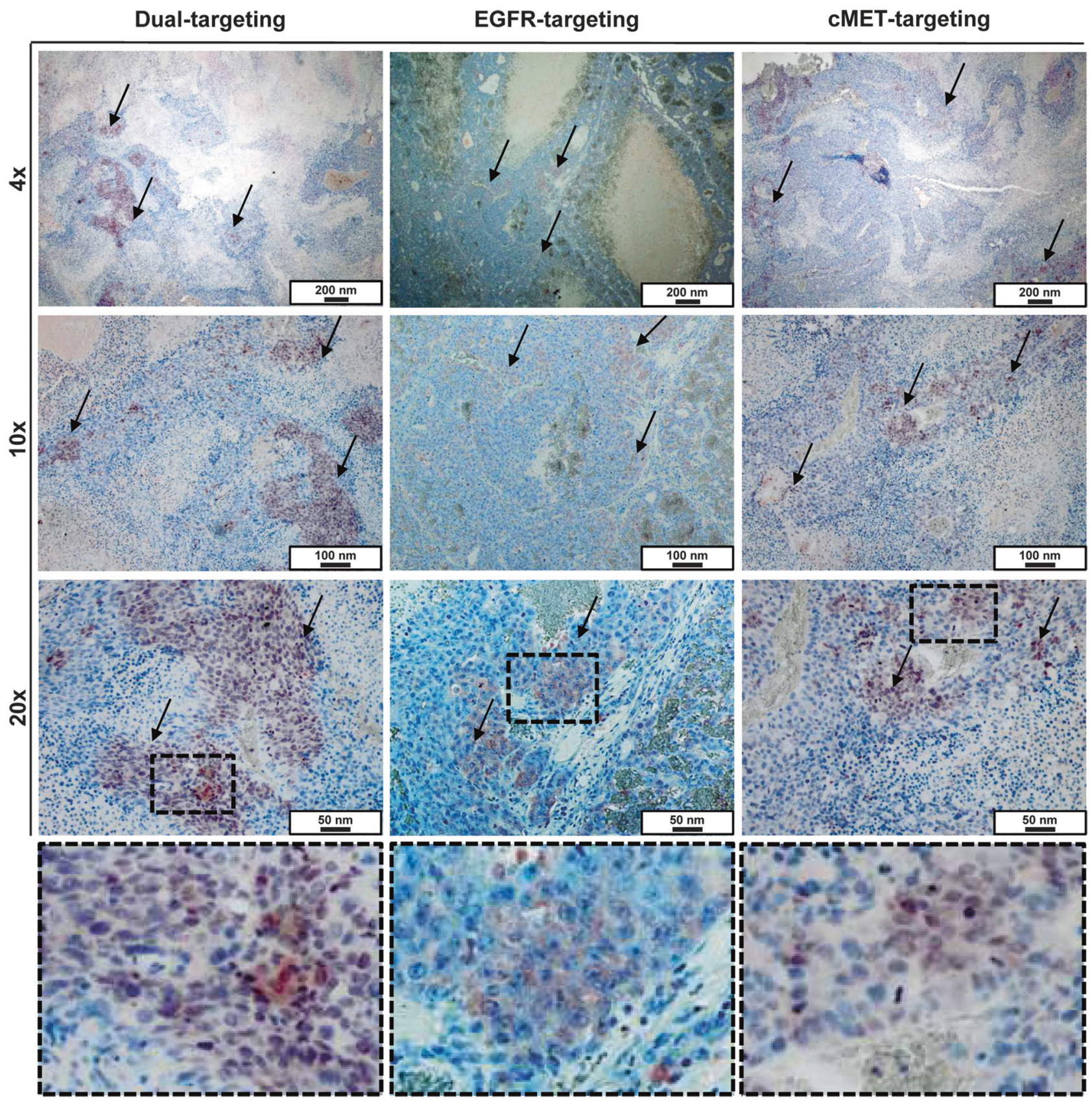

Fig. 5 Immunohistochemical NIS staining. Paraffin embedded tumor sections were immunohistochemically stained for NIS expression. Tumors from mice treated with polyplexes for dual-targeting revealed clusters of membrane-associated as well as cytoplasmatic NIS gene expression around blood vessels in the tumorous tissue. Animals that were injected with polyplexes for single EGFR- and cMET-targeting showed NIS-specific immunoreactivity as well that correlated with PET imaging data of different antibodies and chemotherapeutics with different modes of action to circumvent resistance and enhance efficacy. Thinking along the same lines, a dual-targeting approach was performed in this study focusing on simultaneously targeting the two receptors EGFR and cMET. EGFR and cMET overexpression in many different cancer types, which is often accompanied with poor prognosis, provide the basis for this approach with the aim of increasing the efficacy of targeting and transduction in heterogeneic tumors. Two underlying mechanisms that enhance binding and uptake of polyplexes for dual-targeting are conceivable: (1) the dual approach may mimic virus-like particles that use more than one receptor for uptake $[9,19]$ and (2) receptor crosslinking may trigger enhanced endocytosis and particle uptake into the lysosome and trafficking to the cell nucleus [12]. 

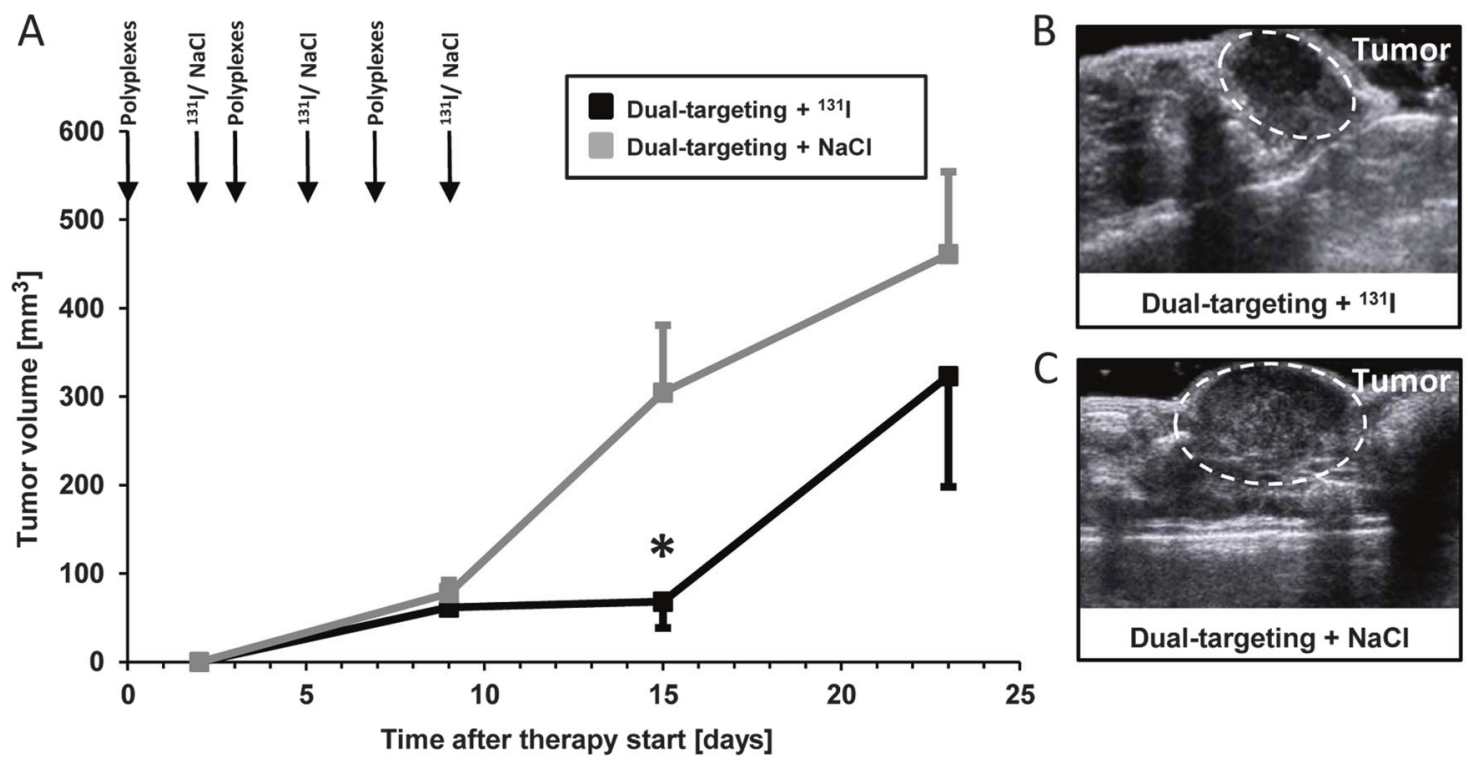

C

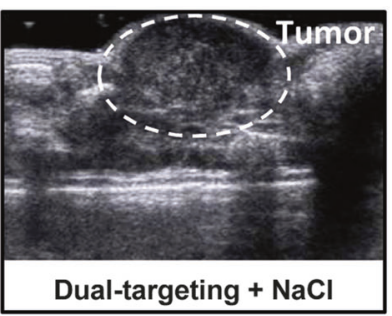

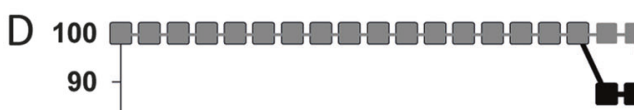

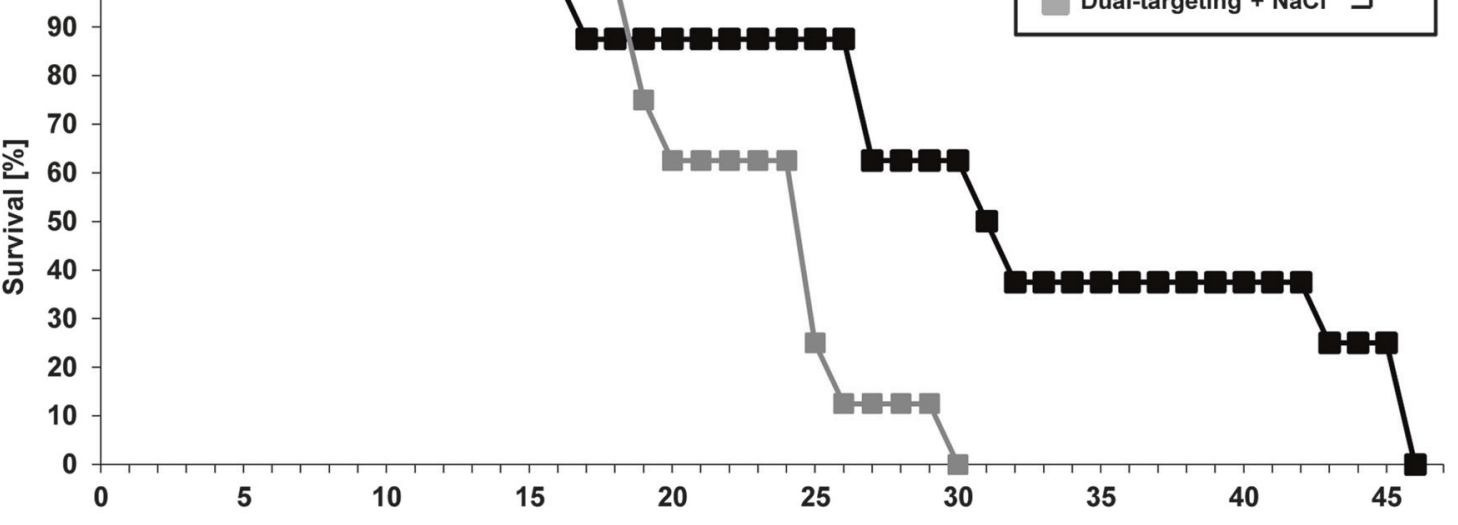

Time after therapy start [days]

E

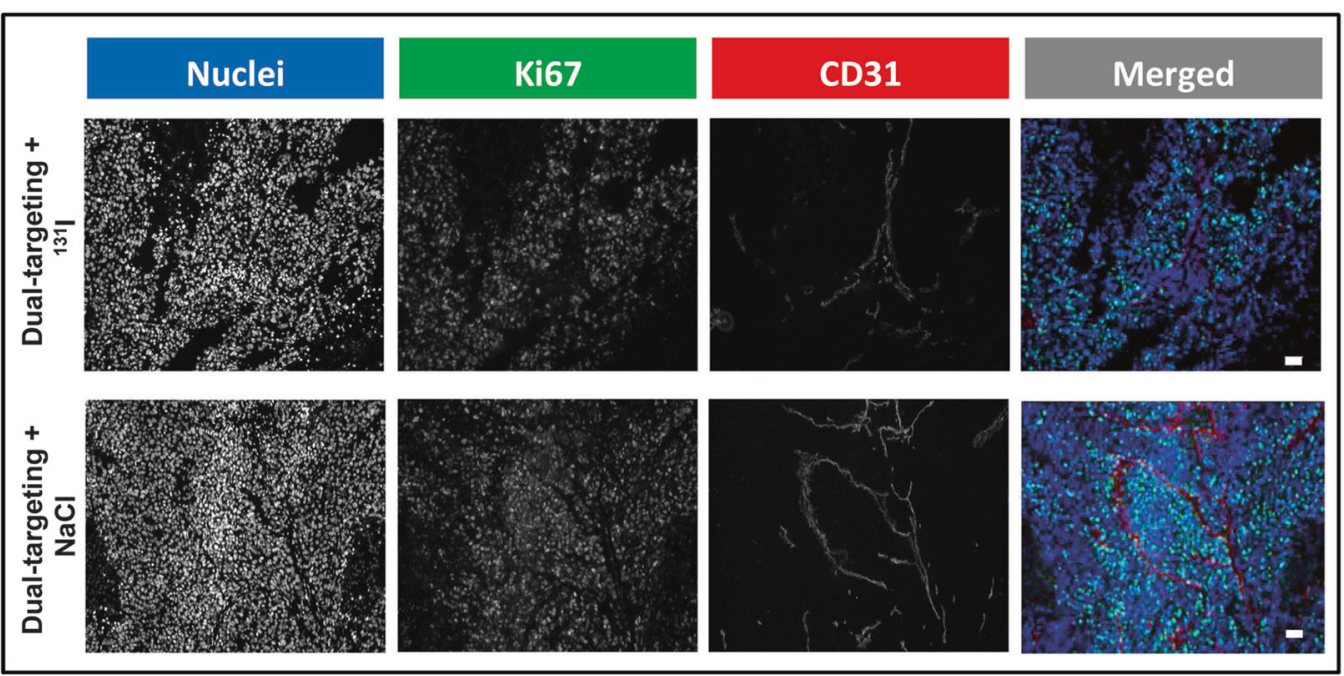


Fig. 6 Iodide therapy studies after dual-targeting of EGFR and cMET. The therapeutic effect of the dual-targeted NIS gene therapy approach after application of ${ }^{131} \mathrm{I}$ was assessed. Three weeks after tumor cell inoculation, mice received three cycles of polyplexes for dual-targeting i.v., followed by i.p. injections of $55.5 \mathrm{MBq}{ }^{131} \mathrm{I}(n=8)$. Control mice received saline instead of the therapeutic iodide $(n=8)$. Animals treated with polyplexes for dual-targeting that received radioiodide showed reduced tumor growth during and after therapy $(\mathbf{a}, \mathbf{b})$ assessed by conventional sonography in comparison to animals that received saline instead (a, c) $(* p \leq 0.05)$. This was accompanied by significantly enhanced survival in the therapy group (d) $(* p \leq 0.05)$. Immunofluorescence analysis of tumors after therapy revealed reduced proliferation (Ki67, green) and blood vessel density (CD31, red) in mice that received the cytotoxic iodide compared to tumors of mice treated with saline (e). Results are reported as mean \pm SEM or percent for the survival plot

As small peptide ligands exhibit favorable characteristics compared to large proteins and antibodies as targeting ligands due to synthesis procedures, the small peptide ligands GE11 for EGFR-targeting and cMBP for cMETtargeting were coupled to a well-established LPEI-PEG $\mathrm{kDa}^{-}$ backbone in this study. LPEI-based polymers have already been applied in clinical trials [53-55]. Both ligands demonstrated high tumor specificity with high targeting efficacy in former studies [6-10]. The polyplexes are formed by mixing NIS DNA with either 100\% LPEI-PEG-
GE11 or $100 \%$ LPEI-PEG-cMBP for single-receptor targeting or with a solution of polymers containing 50\% LPEIPEG-GE11 and 50\% LPEI-PEG-cMBP at a total N/P ratio of 6 for dual-targeting.

To exclude differences in particle formation and size between polyplexes for single- or dual-targeting that may have an impact on transduction efficiency, polyplex solutions were examined by TEM. All three solutions exhibited comparable sizes of round and linear formed particles ranging from 50 to $200 \mathrm{~nm}$. For particles with these sizes cellular uptake is described to occur via a clathrindependent endocytosis pathway [56]. Detailed analysis of binding and uptake of polyplexes after single-receptor and dual-receptor targeting was performed by flow cytometry with labeled NIS DNA in three different cell lines. The $\mathrm{HCC}$ cell line $\mathrm{HuH7}$ as well as the breast cancer cell line MCF-7 showed high EGFR and cMET expression, whereas for the thyroid carcinoma cell line FTC-133 low expression of both surface receptors was detected in vitro. An incubation time of $45 \mathrm{~min}$ for in vitro experiments was chosen, as this allows a more accurate determination of receptormediated cellular binding and uptake measured by flow cytometry as well as by NIS-mediated iodide uptake. Longer transfection times may result in a higher rate of unspecific binding and transfection masking the ligand-
Fig. 7 Perfusion of intrahepatic tumors determined by CEUS. Tumors of mice treated with polyplexes for dual-targeting that received $55.5 \mathrm{MBq}{ }^{131} \mathrm{I}$ $(n=4)$ demonstrated an overall reduced contrast agent uptake expressed in arbitrary units (a.u.) compared to mice that received saline instead (a) $(n=3)$.

Further, tumors of therapy mice showed reduced peak

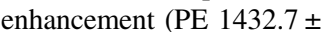
$534.6(\mathbf{b}))$, wash-in area under the curve (WiAUC 7184.2 \pm 2197.6 (c)) and retention time (RT $7.98 \pm 0.97$ (d)) after radioiodide therapy as compared to control animals (PE: $2425.9 \pm$ 260.5; WiAUC: $19633.4 \pm$ 1451.8; RT: $11.39 \pm 0.71(\mathbf{b}-\mathbf{d})$ ). Results are expressed as mean \pm SEM $(* p \leq 0.05 ; * * p \leq 0.01)$
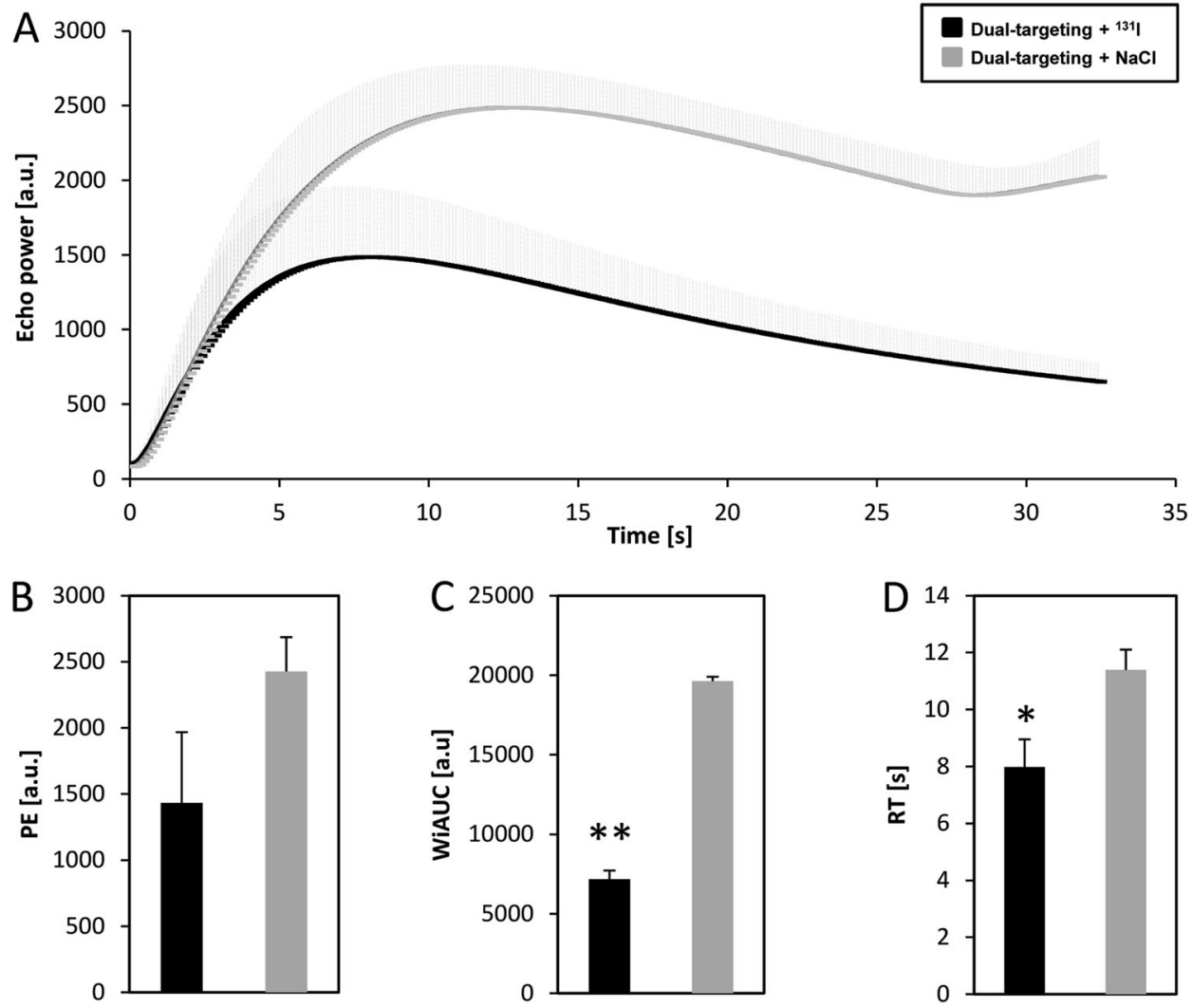
mediated polyplex uptake. For detecting receptor expression levels, flow cytometry was performed with receptor specific antibodies. For receptor specific targeting with polyplexes, peptides were used. The peptide GE11 is a lowaffinity peptide ligand that only effectively binds in multivalent form [57]. In addition, EGFR-mediated uptake was found to be less effective than by natural EGF [58]. In contrast, cMBP was previously characterized as very effective cMET binding and internalizing peptide ligand $[5,6,10]$.

HuH7 and MCF-7 exhibited higher cellular binding and uptake capacity after simultaneous dual-targeting, which correlated well with iodide uptake levels, compared to results obtained after targeting only one receptor. The low EGFR and cMET-expressing cell line FTC-133, however, did not show any advantage of dual-targeting over singletargeting, confirming that improved transfection efficiency is ligand-dependent and the effect cannot be reproduced in low receptor expressing cells.

As a next step, the reporter function of NIS was used for detailed investigation of NIS gene expression in vivo in orthotopic HuH7 HCC tumors by noninvasive small-animal PET-imaging using ${ }^{124} \mathrm{I}$ as tracer. A beneficial effect of the dual-targeting strategy over both single-targeting approaches was detected. Images of mice that received dualtargeted polyplexes showed more pronounced levels of NIS-mediated radioiodine uptake in the tumor lesion. Quantification of iodide uptake revealed higher levels after dual-targeting at all imaging time points. Interestingly, single EGFR-targeting showed higher levels of radioiodide uptake $1 \mathrm{~h}$ after tracer application compared to cMETtargeting. After $3 \mathrm{~h}$, tumors of both single-targeting approaches showed nearly the same tumoral iodide uptake levels. With dual-targeting an $\sim 1 \%$ of ID higher uptake was achieved. After $5 \mathrm{~h}$, EGFR-targeting had dropped down more rapidly showing higher levels of iodide efflux and therefore lower iodide retention as compared to dual and cMET-targeting. This is crucial for more effective therapeutic application of ${ }^{131} \mathrm{I}$, as iodide retention is an essential factor to reach a sufficiently high tumor-absorbed dose, especially in the absence of iodide organification in liver tumors [59].

Immunohistochemical staining showed tumorous NIS protein expression in all three treatment groups after application of polyplexes. NIS-specific immunostaining was mainly located in the vicinity of blood vessels and occurred in typical clusters. A trend toward more intensive and expanded areas of NIS-specific immunostaining was seen in sections of animals that received polyplexes for dual-targeting.

After confirming the beneficial effect of dual-targeting in vivo by imaging of biodistribution and levels of NIS expression, the therapeutic efficacy of this NIS gene delivery strategy was evaluated. Animals were treated with dual-targeted polyplexes followed by application of ${ }^{131} \mathrm{I} 48$ $\mathrm{h}$ later. As control group, animals received saline instead of the therapeutic radioiodide. The therapy regimen was performed according to an established treatment protocol with three treatment circles and $48 \mathrm{~h}$ between NIS gene delivery and radioiodide application $[6,18]$ that allows comparison to earlier studies. Tumor growth of orthotopic liver tumors was monitored by conventional sonography and perfusion was assessed by CEUS with the contrast agent SonoVue ${ }^{\circledR}$. Perfusion allows further evaluation of the therapeutic effect compared to tumor growth and survival by showing differences in contrast agent distribution and tumor blood flow. Animals in the therapy group showed significantly reduced tumor growth and prolonged survival. The therapeutic effect was further investigated by comparing tumor cell proliferation and blood vessel density of the therapy and control group ex vivo. Reduced proliferation and a lower amount of blood vessels in tumor sections of therapy animals that received ${ }^{131} \mathrm{I}$ correlated with the reduced progression of the intrahepatic tumors. CEUS perfusion data, which showed reduced peak enhancement, lower wash-in area under the curve and lower retention times in tumors of therapy animals that show lower blood vessel formation complemented the results and confirm the enormous therapeutic efficacy of dual-targeted NIS gene therapy.

We are aware that this study has limitations as the comparison of single vs. dual-targeting in a xenograft tumor model that concurrently expresses both targeting receptors at high levels in a homogenous manner is not an ideal model for evaluation of the benefits of the dual-targeting approach in heterogeneic tumors.

However, this study represents the first step toward improving the polyplex-mediated NIS gene therapy concept by taking into account tumor heterogeneity as one of the major obstacles for any kind of targeted therapy. Our study is able to demonstrate that the dual-targeting of cMET and EGFR for tumor-specific polyplex-mediated NIS gene transfer results in highly effective induction of significant amounts of radioiodine with a significant therapeutic effect of ${ }^{131} \mathrm{I}$ as shown by detailed in vitro and in vivo studies. Also, in vitro as well as in vivo imaging studies show enhanced efficacy of the dual-targeting approach as compared to the single-targeting of cMET or EGFR. This study therefore provides proof-of-principle of the feasibility of systemic NIS gene transfer using a dual-targeting concept with the perspective of effective targeting of polymermediated NIS gene delivery in tumors expressing cMET and/or EGFR at variable levels within the same tumor and within primary and metastatic tumors. For a more robust and quantitative analysis of the superior efficacy of dualtargeted polymers as compared to single-targeted polymers 
in the context of NIS gene therapy, further experiments are planned in tumor models that more reliably reflect the complexity of tumor heterogeneity, which, however, is beyond the scope of the current study.

In conclusion, this novel simultaneous targeting approach of EGFR and cMET for NIS gene delivery to HCC tumors combines two crucial bispecific approaches: NIS with its innate dual characteristics to function as reporter gene for diagnostic evaluation and as therapeutic gene in synergy with dual-targeting of two receptors that results in enhanced cellular uptake and increased NIS gene expression in the tumor lesion. Our results highlight the benefits of the bifunctional strategy that represents a promising concept for future clinical translation providing two major advantages for clinical application, enhancing safety by molecular imaging of biodistribution and levels of gene expression as well as overcoming the limitations through tumor heterogeneity by designing polyplexes that home to several targets.

Acknowledgements We are grateful to Sissy M. Jhiang (Ohio State University, Columbus, OH, USA) for supplying the full length human NIS cDNA. We thank Barbara von Ungern-Sternberg, Rosel Oos and Karin Bormann-Giglmaier (Department of Nuclear Medicine, University Hospital of Munich, LMU Munich, Munich, Germany) for their assistance with animal care and imaging studies. We thank Michael Ingrisch for assistance with CEUS analysis.

Funding This work was supported by grants from the Deutsche Forschungsgemeinschaft within the Collaborative Research Center SFB824 (project C 08) to CS as well as within the Priority Programme SPP1629 to CS (SP 581/6-1, SP581/6-2), the Cluster of Excellence Nanosystems Initiative Munich (NIM) to EW and by a grant from the Wilhelm-Sander-Stiftung to CS (2014.129.1).

\section{Compliance with ethical standards}

Conflict of interest The authors declare that they have no conflict of interest.

Publisher's note: Springer Nature remains neutral with regard to jurisdictional claims in published maps and institutional affiliations.

\section{References}

1. Davis GL, Dempster J, Meler JD, Orr DW, Walberg MW, Brown B, et al. Hepatocellular carcinoma: management of an increasingly common problem. Proc (Bayl Univ Med Cent). 2008;21:266-80.

2. Lu LC, Hsu CH, Hsu C, Cheng AL. Tumor heterogeneity in hepatocellular carcinoma: facing the challenges. Liver Cancer. 2016;5:128-38.

3. Hammoud GM, Ibdah JA. Are we getting closer to understanding intratumor heterogeneity in hepatocellular carcinoma? Hepatobiliary Surg Nutr. 2016;5:188-90.

4. Al-Lazikani B, Banerji U, Workman P. Combinatorial drug therapy for cancer in the post-genomic era. Nat Biotechnol. 2012;30:679-92.
5. Broda E, Mickler FM, Lachelt U, Morys S, Wagner E, Brauchle C. Assessing potential peptide targeting ligands by quantification of cellular adhesion of model nanoparticles under flow conditions. J Control Release. 2015;213:79-85.

6. Urnauer S, Morys S, Krhac Levacic A, Muller AM, Schug C, Schmohl KA, et al. Sequence-defined cMET/HGFR-targeted Polymers as gene delivery vehicles for the theranostic sodium iodide symporter (NIS) gene. Mol Ther. 2016;24:1395-404.

7. Klutz K, Schaffert D, Willhauck MJ, Grunwald GK, Haase R, Wunderlich N, et al. Epidermal growth factor receptor-targeted (131)I-therapy of liver cancer following systemic delivery of the sodium iodide symporter gene. Mol Ther. 2011;19:676-85.

8. Schmohl KA, Gupta A, Grunwald GK, Trajkovic-Arsic M, Klutz $\mathrm{K}$, Braren $\mathrm{R}$, et al. Imaging and targeted therapy of pancreatic ductal adenocarcinoma using the theranostic sodium iodide symporter (NIS) gene. Oncotarget. 2017;8:33393-404.

9. Kos P, Lachelt U, He D, Nie Y, Gu Z, Wagner E. Dual-targeted polyplexes based on sequence-defined peptide-PEG-oligoamino amides. J Pharm Sci. 2015;104:464-75.

10. Kos P, Lachelt U, Herrmann A, Mickler FM, Doblinger M, He D, et al. Histidine-rich stabilized polyplexes for cMet-directed tumortargeted gene transfer. Nanoscale. 2015;7:5350-62.

11. Stabile LP, Rothstein ME, Keohavong P, Lenzner D, Land SR, Gaither-Davis AL, et al. Targeting of both the c-Met and EGFR pathways results in additive inhibition of lung tumorigenesis in transgenic mice. Cancers. 2010;2:2153-70.

12. Moody PR, Sayers EJ, Magnusson JP, Alexander C, Borri P, Watson P, et al. Receptor crosslinking: a general method to trigger internalization and lysosomal targeting of therapeutic receptor: ligand complexes. Mol Ther. 2015;23:1888-98.

13. Jo M, Stolz DB, Esplen JE, Dorko K, Michalopoulos GK, Strom SC. Cross-talk between epidermal growth factor receptor and cMet signal pathways in transformed cells. J Biol Chem. 2000;275:8806-11.

14. Puri N, Salgia R. Synergism of EGFR and c-Met pathways, crosstalk and inhibition, in non-small cell lung cancer. J Carcinog. 2008;7:9.

15. Quader S, Kataoka K. Nanomaterial-enabled cancer therapy. Mol Ther. 2017;25:1501-13.

16. Schaffert D, Kiss M, Rodl W, Shir A, Levitzki A, Ogris M, et al. Poly(I:C)-mediated tumor growth suppression in EGF-receptor overexpressing tumors using EGF-polyethylene glycol-linear polyethylenimine as carrier. Pharm Res. 2011;28:731-41.

17. Schaffert D, Ogris M. Nucleic acid carrier systems based on polyethylenimine conjugates for the treatment of metastatic tumors. Curr Med Chem. 2013;20:3456-70.

18. Urnauer S, Klutz K, Grunwald GK, Morys S, Schwenk N, Zach C, et al. Systemic tumor-targeted sodium iodide symporter (NIS) gene therapy of hepatocellular carcinoma mediated by B6 peptide polyplexes. J Gene Med. 2017;19:e2957.

19. Nie Y, Schaffert D, Rodl W, Ogris M, Wagner E, Gunther M. Dual-targeted polyplexes: one step towards a synthetic virus for cancer gene therapy. J Control Release. 2011;152:127-34.

20. Saeidnia S, Manayi A, Abdollahi M. From in vitro experiments to in vivo and clinical studies; pros and cons. Curr Drug Discov Technol. 2015;12:218-24.

21. Dai G, Levy O, Carrasco N. Cloning and characterization of the thyroid iodide transporter. Nature. 1996;379:458-60.

22. Spitzweg C, Zhang S, Bergert ER, Castro MR, McIver B, Heufelder AE, et al. Prostate-specific antigen (PSA) promoter-driven androgen-inducible expression of sodium iodide symporter in prostate cancer cell lines. Cancer Res. 1999;59:2136-41.

23. Dwyer RM, Schatz SM, Bergert ER, Myers RM, Harvey ME, Classic KL, et al. A preclinical large animal model of adenovirusmediated expression of the sodium-iodide symporter for 
radioiodide imaging and therapy of locally recurrent prostate cancer. Mol Ther. 2005;12:835-41.

24. Penheiter AR, Wegman TR, Classic KL, Dingli D, Bender CE, Russell SJ, et al. Sodium iodide symporter (NIS)-mediated radiovirotherapy for pancreatic cancer. AJR Am J Roentgenol. 2010;195:341-9.

25. Penheiter AR, Dingli D, Bender CE, Russell SJ, Carlson SK. Monitoring the initial delivery of an oncolytic measles virus encoding the human sodium iodide symporter to solid tumors using contrast-enhanced computed tomography. J Gene Med. 2012;14:590-7.

26. Barton KN, Stricker H, Brown SL, Elshaikh M, Aref I, Lu M, et al. Phase I study of noninvasive imaging of adenovirusmediated gene expression in the human prostate. Mol Ther. 2008;16:1761-9.

27. Barton KN, Stricker H, Elshaikh MA, Pegg J, Cheng J, Zhang Y, et al. Feasibility of adenovirus-mediated hNIS gene transfer and ${ }^{131}$ I radioiodine therapy as a definitive treatment for localized prostate cancer. Mol Ther. 2011;19:1353-9.

28. Russell SJ, Federspiel MJ, Peng KW, Tong C, Dingli D, Morice WG, et al. Remission of disseminated cancer after systemic oncolytic virotherapy. Mayo Clin Proc. 2014;89:926-33.

29. Klutz K, Willhauck MJ, Wunderlich N, Zach C, Anton M, Senekowitsch-Schmidtke R, et al. Sodium iodide symporter (NIS)-mediated radionuclide $\left({ }^{131} \mathrm{I},{ }^{188} \mathrm{Re}\right)$ therapy of liver cancer after transcriptionally targeted intratumoral in vivo NIS gene delivery. Hum Gene Ther. 2011;22:1403-12.

30. Willhauck MJ, Samani BR, Wolf I, Senekowitsch-Schmidtke R, Stark HJ, Meyer GJ, et al. The potential of 211Astatine for NISmediated radionuclide therapy in prostate cancer. Eur J Nucl Med Mol Imaging. 2008;35:1272-81.

31. Russ V, Elfberg H, Thoma C, Kloeckner J, Ogris M, Wagner E. Novel degradable oligoethylenimine acrylate ester-based pseudodendrimers for in vitro and in vivo gene transfer. Gene Ther. 2008; 15:18-29.

32. Spitzweg C, Baker CH, Bergert ER, O'Connor MK, Morris JC. Image-guided radioiodide therapy of medullary thyroid cancer after carcinoembryonic antigen promoter-targeted sodium iodide symporter gene expression. Hum Gene Ther. 2007;18:916-24.

33. Knoop K, Kolokythas M, Klutz K, Willhauck MJ, Wunderlich N, Draganovici D, et al. Image-guided, tumor stroma-targeted 131I therapy of hepatocellular cancer after systemic mesenchymal stem cell-mediated NIS gene delivery. Mol Ther. 2011;19:1704-13.

34. Müller AM, Schmohl KA, Knoop K, Schug C, Urnauer S, Hagenhoff A, et al. Hypoxia-targeted ${ }^{131}$ I therapy of hepatocellular cancer after systemic mesenchymal stem cell-mediated sodium iodide symporter gene delivery. Oncotarget. 2016;7:54795-810.

35. Eichhorn ME, Klotz LV, Luedemann S, Strieth S, Kleespies A, Preissler G, et al. Vascular targeting tumor therapy: non-invasive contrast enhanced ultrasound for quantitative assessment of tumor microcirculation. Cancer Biol Ther. 2010;9:794-802.

36. Ravera S, Reyna-Neyra A, Ferrandino G, Amzel LM, Carrasco N. The sodium/iodide symporter (NIS): molecular physiology and preclinical and clinical applications. Annu Rev Physiol. 2017;79:261-89.

37. Trujillo MA, Oneal MJ, McDonough S, Qin R, Morris JC. A steep radioiodine dose response scalable to humans in sodium-iodide symporter (NIS)-mediated radiovirotherapy for prostate cancer. Cancer gene Ther. 2012;19:839-44.

38. Willhauck MJ, Sharif Samani BR, Klutz K, Cengic N, Wolf I, Mohr L, et al. Alpha-fetoprotein promoter-targeted sodium iodide symporter gene therapy of hepatocellular carcinoma. Gene Ther. 2008;15:214-23.

39. Klutz K, Russ V, Willhauck MJ, Wunderlich N, Zach C, Gildehaus FJ, et al. Targeted radioiodine therapy of neuroblastoma tumors following systemic nonviral delivery of the sodium iodide symporter gene. Clin Cancer Res. 2009;15:6079-86.

40. Klutz K, Willhauck MJ, Dohmen C, Wunderlich N, Knoop K, Zach $C$, et al. Image-guided tumor-selective radioiodine therapy of liver cancer after systemic nonviral delivery of the sodium iodide symporter gene. Hum Gene Ther. 2011;22: 1563-74.

41. Grünwald GK, Klutz K, Willhauck MJ, Schwenk N, Senekowitsch-Schmidtke R, Schwaiger M, et al. Sodium iodide symporter (NIS)-mediated radiovirotherapy of hepatocellular cancer using a conditionally replicating adenovirus. Gene Ther. 2013;20:625-33.

42. Grünwald GK, Vetter A, Klutz K, Willhauck MJ, Schwenk N, Senekowitsch-Schmidtke R, et al. EGFR-targeted adenovirus dendrimer coating for improved systemic delivery of the theranostic NIS gene. Mol Ther Nucleic Acids. 2013;2: e131.

43. Grünwald GK, Vetter A, Klutz K, Willhauck MJ, Schwenk N, Senekowitsch-Schmidtke R, et al. Systemic image-guided liver cancer radiovirotherapy using dendrimer-coated adenovirus encoding the sodium iodide symporter as theranostic gene. J Nucl Med. 2013;54:1450-7.

44. Spitzweg C, O'Connor MK, Bergert ER, Tindall DJ, Young CY, Morris JC. Treatment of prostate cancer by radioiodine therapy after tissue-specific expression of the sodium iodide symporter. Cancer Res. 2000;60:6526-30.

45. Jamal-Hanjani M, Quezada SA, Larkin J, Swanton C. Translational implications of tumor heterogeneity. Clin Cancer Res. 2015;21:1258-66.

46. Swanton C. Intratumor heterogeneity: evolution through space and time. Cancer Res. 2012;72:4875-82.

47. O'Connor JP, Rose CJ, Waterton JC, Carano RA, Parker GJ, Jackson A. Imaging intratumor heterogeneity: role in therapy response, resistance, and clinical outcome. Clin Cancer Res. 2015;21:249-57.

48. Junttila MR, de Sauvage FJ. Influence of tumour microenvironment heterogeneity on therapeutic response. Nature. 2013;501:346-54.

49. Huang A, Zhao X, Yang XR, Li FQ, Zhou XL, Wu K, et al. Circumventing intratumoral heterogeneity to identify potential therapeutic targets in hepatocellular carcinoma. J Hepatol. 2017;67:293-301.

50. Siddique O, Yoo ER, Perumpail RB, Perumpail BJ, Liu A, Cholankeril G, et al. The importance of a multidisciplinary approach to hepatocellular carcinoma. J Multidiscip Healthc. 2017;10:95-100.

51. Hectors SJ, Wagner M, Bane O, Besa C, Lewis S, Remark R, et al. Quantification of hepatocellular carcinoma heterogeneity with multiparametric magnetic resonance imaging. Sci Rep. 2017;7:2452.

52. El-Khoueiry AB, Sangro B, Yau T, Crocenzi TS, Kudo M, Hsu C, et al. Nivolumab in patients with advanced hepatocellular carcinoma (CheckMate 040): an open-label, non-comparative, phase 1/ 2 dose escalation and expansion trial. Lancet. 2017;389:2492502.

53. Sidi AA, Ohana $P$, Benjamin S, Shalev M, Ransom JH, Lamm D, et al. Phase I/II marker lesion study of intravesical BC819 DNA plasmid in H19 over expressing superficial bladder cancer refractory to bacillus Calmette-Guerin. J Urol. 2008;180:2379-83.

54. Gofrit ON, Benjamin S, Halachmi S, Leibovitch I, Dotan Z, Lamm DL, et al. DNA based therapy with diphtheria toxin-A BC-819: a phase $2 \mathrm{~b}$ marker lesion trial in patients with intermediate risk nonmuscle invasive bladder cancer. J Urol. 2014; 191:1697-702. 
55. Anwer K, Barnes MN, Fewell J, Lewis DH, Alvarez RD. Phase-I clinical trial of IL-12 plasmid/lipopolymer complexes for the treatment of recurrent ovarian cancer. Gene Ther. 2010;17:360-9.

56. Rejman J, Bragonzi A, Conese M. Role of clathrin- and caveolaemediated endocytosis in gene transfer mediated by lipo- and polyplexes. Mol Ther. 2005;12:468-74.

57. Abourbeh G, Shir A, Mishani E, Ogris M, Rodl W, Wagner E, et al. PolyIC GE11 polyplex inhibits EGFR-overexpressing tumors. IUBMB Life. 2012;64:324-30.
58. Mickler FM, Mockl L, Ruthardt N, Ogris M, Wagner E, Brauchle C. Tuning nanoparticle uptake: live-cell imaging reveals two distinct endocytosis mechanisms mediated by natural and artificial EGFR targeting ligand. Nano Lett. 2012;12: 3417-23.

59. Portulano C, Paroder-Belenitsky M, Carrasco N. The $\mathrm{Na}^{+} / \mathrm{I}^{-}$ symporter (NIS): mechanism and medical impact. Endocr Rev. 2014;35:106-49. 